\title{
Percepção de professores sobre a avaliação de habilidades motoras e de processo - versão escolar aplicada aos alunos com deficiência física*
}

\section{Teachers' perception about the school-version of the assessment of motor and process skills applied to disabled students}

\author{
Luciana Ramos Baleotti ${ }^{1}$, Mariana Dutra Zafani ${ }^{2}$, Maria das Graças \\ Abreu de Faria ${ }^{3}$, Lívia de Castro Magalhães ${ }^{4}$
}

BALEOTTI, L. R.; ZAFANI, M. D.; FARIA, M. G. A.; MAGALHÃES, L. C. Percepção de professores sobre a avaliação de habilidades motoras e de processo - versão escolar aplicada aos alunos com deficiência física. Rev. Ter. Ocup. Univ. São Paulo, v. 22, n. 1, p. 1-9, jan./abr. 2011.

\begin{abstract}
RESUMO: Objetivou-se verificar sob a ótica do professor se a Avaliação de Habilidades Motoras e de Processo - Versão Escolar (School - Version of the Assessment of Motor and Process Skills School-AMPS) aplicada aos alunos com deficiência física prediz o desempenho do aluno observado em sala de aula. Participaram dez crianças com deficiência física, entre quatro e oito anos de idade, e seus respectivos educadores. Os dados foram coletados por meio da observação das crianças em ambiente clínico durante a realização de tarefas pré-determinadas, com base na versão brasileira da School-AMPS. Aos educadores foi apresentado um relatório de avaliação da criança e aplicado um questionário composto por três questões. Os dados foram analisados de forma quantitativa e qualitativa. Os resultados apontaram que a School-AMPS possibilitou identificar se o desempenho da criança foi, na sua maioria, considerado deficitário, satisfatório ou intermediário e, sobretudo, possibilitou analisar o desempenho a partir da percepção da relação existente entre demandas da pessoa, da tarefa e do ambiente. Os educadores consideraram que o relatório de avaliação apresentado prediz de forma compatível o desempenho do aluno observado em sala de aula. Consideraram viáveis os recursos pedagógicos adaptados e as sugestões de estratégias para minimizar e/ou superar as dificuldades observadas no desempenho do aluno. Conclui-se que a versão brasileira da School-AMPS tem potencial como medida de desempenho funcional em crianças com deficiência física, entre quatro e oito anos de idade, e pode contribuir para a atuação do terapeuta ocupacional no contexto escolar.
\end{abstract}

DESCRITORES: Educação especial; Pessoas com deficiência; Terapia Ocupacional.

\footnotetext{
* Este estudo é parte de um estudo mais amplo com vistas à validação e padronização da School-AMPS. Apoio: FAPESP.

Resultados parciais deste estudo foram apresentados durante a 10a Jornada de Educação Especial - Educação Especial e o uso das tecnologias da informação e comunicações em práticas pedagógicas inclusivas, promovida pelo departamento de Educação Especial da Faculdade de Filosofia e Ciências - UNESP - Campus de Marília, 18 a 20 de maio de 2010, IV Congresso Brasileiro de Educação Especial e IV Encontro da Associação de Pesquisadores em Educação Especial, promovidos pelo Programa de Pós- Graduação em Educação Especial - PPGEEs da Universidade Federal de São Carlos e pela Associação Brasileira de Pesquisadores em Educação Especial - ABPEE, realizados na Universidade Federal de São Carlos - UFSCAR, no período de 02 a 05 de novembro de 2010.

1. Doutora em Educação, Docente do Curso de Terapia Ocupacional - Departamento de Educação Especial, UNESP, Campus de Marília SP.

2. Terapeuta Ocupacional. Aprimoramento Profissional em "Terapia Ocupacional Aplicada às Necessidades da Educação Especial", UNESP - Marília - SP. Mestrado em Educação - Área de Concentração - Educação Especial (em andamento), UNESP - Marília, SP.

3. Mestre em Ciência da Reabilitação, Terapeuta Ocupacional do Centro de Reabilitação da Prefeitura de Belo Horizonte, MG.

4. Doutora em Educação, Professora do Curso de Terapia Ocupacional, Escola de Educação Física, Fisioterapia e Terapia Ocupacional, Universidade Federal de Minas Gerais - UFMG.

Endereço para correspondência: e-mail - marianadz@ig.com.br
} 


\section{INTRODUÇÃO}

o longo do processo educacional do aluno
com deficiência, em muitos casos, é de
fundamental importância que toda a equipe escolar e em especial os professores recebam suporte de profissionais da área da saúde, para que possam desenvolver um trabalho educacional de qualidade que garanta a participação efetiva de todos os alunos nas atividades escolares. Terapeutas ocupacionais configuram-se como parceiros importantes para o sucesso da inclusão escolar de alunos com deficiência.

O terapeuta ocupacional, por ser um profissional que se dedica ao estudo do desenvolvimento humano, dos processos de aprendizagem e autonomia, possui arcabouço teórico e prático, que o capacita a contribuir para o sucesso do aluno em sala de aula (MUNGUBA, 2007). Por meio da avaliação dos aspectos do desempenho que estão afetando a capacidade do aluno para se engajar nas atividades ocupacionais que ele quer, precisa ou que se espera que desempenhe no contexto escolar, o terapeuta ocupacional atua no sentido de criar estratégias para, na medida das possibilidades, torná-lo mais apto, independente e produtivo.

Baleotti (2006) salienta que ao tratarmos do processo de educação inclusiva é necessária a discussão acerca da importância da parceria entre a saúde e a educação. A Legislação da área da Educação Especial traz explicitamente a necessidade de profissionais da saúde atuarem como parceiros na atenção aos alunos com necessidades educacionais especiais. Nesse sentido, a Resolução CNE/ $\mathrm{CEB} \mathrm{N}^{\circ}$ 2, de 11 de setembro de 2001, que institui Diretrizes Nacionais para a Educação Especial na Educação Básica, enfatiza no artigo $6^{\circ}$, parágrafo III, que:

Art. $6^{\circ}$ Para a identificação das necessidades educacionais especiais dos alunos e a tomada de decisões quanto ao atendimento necessário, a escola deve realizar, com assessoramento técnico, avaliação do aluno no processo de ensino e aprendizagem, contando, para tal, com: III -[...] a cooperação dos serviços de saúde [...]. (RESOLUÇẪO CNE/CEB Nº 2, 2001, p. 2).

Pensando sob esse prisma, terapeutas ocupacionais juntamente com a equipe escolar, devem buscar estratégias que possibilitem a inserção e participação efetiva dos alunos com deficiência ao contexto educacional inclusivo, aprimorando suas habilidades e competências para a aprendizagem.

Baleotti (2006) salienta que é de fundamental importância que as ações desses profissionais sejam pautadas na concepção do modelo sócio-interacionista, e não no modelo médico, no qual a deficiência é interpretada como um atributo inerente ao indivíduo e as ações centramse na pessoa, buscando adaptá-la ás exigências do meio. A autora destaca ainda que a educação inclusiva tem o grande mérito de deslocar a atenção para o meio, ao apontar que as necessidades educacionais especiais não se definem apenas pela origem do problema, mas também pelo tipo de resposta educativa, o tipo de recursos disponíveis e tipo de ajuda que se devem proporcionar aos alunos, a fim de eliminar barreiras e identificar facilitadores para o processo de inclusão.

O papel do terapeuta ocupacional no sistema escolar é o de facilitar o desempenho funcional dos estudantes em atividades escolares de modo que se beneficiem da experiência educativa. Para cumprir esse papel, necessitam contar com instrumentos de avaliação que abordem aspectos relevantes do desempenho funcional do aluno em sala de aula (LAW et al., 2001 apud FINGERHUT et al., 2002).

Nesse sentido, um instrumento de coleta de dados, como a Avaliação de Habilidades Motoras e de Processo - Versão Escolar ou School-AMPS (FARIA; MAGALHÃES, 2006), possibilita um olhar avaliativo diretamente direcionado ao desempenho da criança durante a realização de atividades escolares, o que permite revelar aspectos funcionais que devem ser estimulados no contexto educacional.

A School-AMPS é uma versão modificada da Avaliação das Habilidades Motoras e de Processo (FISHER, 1997 apud ATCHISON et al., 1998) desenvolvida por terapeutas ocupacionais para retratar o desempenho funcional da criança em tarefas de sala de aula.

O processo de construção da School-AMPS, versão escolar, foi iniciado por Magalhães (1995) que adaptou o instrumento para avaliar o desempenho funcional de crianças brasileiras e norte-americanas nas tarefas de sala de aula (apud FARIA, 2004). Em 2004, Faria deu continuidade ao processo de adaptação da School-AMPS para crianças brasileiras de quatro a oito anos de idade. Nesse estudo, a autora concluiu que a Versão Brasileira da School-AMPS é um instrumento que pode ser útil para medir os resultados da intervenção terapêutica ocupacional voltados a facilitar a participação de crianças com necessidades especiais na escola.

A School-AMPS (FARIA; MAGALHÃES, 2006) é composta por duas escalas: a motora, que mede a eficiência da pessoa ao movimentar objetos e a si própria no ambiente e a de processo que mede a eficiência do indivíduo em organizar ações e concluir uma tarefa resolvendo possíveis problemas (FARIA, 2004). O desempenho da criança é pontuado nestas duas escalas, que são compostas por 
taxonomias de verbos de ação. $\mathrm{O}$ escore para cada verbo de ação pode variar de 1 a 4, sendo: 1- deficiente, 2- ineficiente, 3- questionável e 4- competente (FARIA; MAGALHÃES, 2006).

Para avaliar as crianças com deficiência física e compreender seus níveis de função na ocupação o terapeuta ocupacional deve contar com instrumentos de avaliação padronizados. A School-AMPS (FARIA; MAGALHÃES, 2006) tem muito a colaborar para a atuação do terapeuta ocupacional no contexto educacional, pois permite a apreciação das habilidades e dificuldades do aluno durante o desempenho de tarefas escolares, tanto do ponto de vista motor quanto de processo. Representa, portanto, um instrumento de avaliação extremamente útil para terapeutas ocupacionais que buscam contribuir para o sucesso escolar de todo e qualquer aluno, incluindo aqui os alunos com deficiência.

A School-AMPS (FARIA; MAGALHÃES, 2006) auxilia a refletir sobre a qualidade e o modo como a tarefa é desempenhada pelo aluno na escola, por fornecer uma análise sistemática da relação entre aluno, tarefa escolar e ambiente escolar. Os dados de avaliação obtidos por este instrumento evidenciam as habilidades e potencialidades do aluno durante a realização de atividade, revela os aspectos funcionais que devem ser estimulados no contexto educacional, bem como os possíveis recursos que poderão auxiliar o seu desempenho, colaborando para elaboração de estratégias e/ou intervenções que podem ser implementadas diretamente no ambiente escolar.

Sabe-se que o terapeuta ocupacional é um dos profissionais da área da saúde que pode contribuir para a inserção e permanência de alunos com deficiência em contextos socioeducacionais regulares. Nesse sentido, o objetivo fundamental deste estudo foi o de investigar a utilidade clinica de se avaliar as habilidades motoras e de processo de alunos com deficiência física por meio da School-AMPS, complementando-a com a devolutiva ao educador acerca de estratégias educacionais que podem ser implementadas em sala de aula. Mais especificamente, o presente estudo teve como objetivo verificar, sob a ótica do professor, se a avaliação de habilidades motoras e de processo aplicada aos alunos com deficiência física em ambiente clínico prediz o desempenho observado em sala de aula.

\section{PROCEDIMENTOS METODOLÓGICOS}

O presente estudo foi aprovado pelo Comitê de ética em Pesquisa da Faculdade de Filosofia e Ciências da Universidade Estadual Paulista - FFC/UNESP/Marília SP sob o protocolo de número 439/2009.
Os responsáveis pelas crianças foram esclarecidos sobre o objetivo e os procedimentos do estudo, assegurandolhes o direito a não participar da pesquisa, ao anonimato, inclusive na divulgação da mesma. Todos assinaram o Termo de Consentimento Livre e Esclarecido.

Este estudo foi desenvolvido em uma cidade do interior do Estado de São Paulo durante o período de março a dezembro de 2009.

Participaram do estudo dez crianças com deficiência física, com idade variando de quatro a oito anos, com seus respectivos professores. As crianças foram recrutadas nos serviços de terapia ocupacional e de fisioterapia de uma clínica escola vinculada a uma universidade pública, e os professores nas respectivas escolas das crianças.

Foram incluídas crianças com desordens neuromotoras advindas de seqüelas de paralisia cerebral, classificadas como apresentando quadros de espasticidades, nas formas hemiplégica, diplégica e quadriplégica, além de crianças com ataxia e com anomalias congênitas. Salientase que a heterogeneidade na seleção dos participantes se fez necessária em virtude de que no contexto escolar encontram-se crianças com diversos quadros motores, assim é extremamente válido contemplar essa diversidade de alunos com deficiência ao aplicar um instrumento que visa contribuir para facilitar a participação no contexto escolar. Foram excluídas crianças com deficiências motoras e intelectuais graves, pois por se tratar de uma avaliação do desempenho de tarefas escolares era necessário que tivessem condições intelectuais para entenderem o que lhes era solicitado. Foram excluídas também crianças com visão subnormal, cegueira e/ou surdez associada.

As crianças foram avaliadas nos locais em que eram atendidas, os professores responderam ao questionário na escola onde atuavam.

Para avaliação das crianças foi utilizada a versão brasileira da School-AMPS para crianças brasileiras de 4 a 8 anos (FARIA, 2004) que é composta por duas escalas: a de habilidades motoras com 16 itens e a de habilidades de processo com 20 itens. Neste estudo, replicou-se rigorosamente os procedimentos descritos por Faria (2004) em seu estudo acerca da adaptação da School-AMPS para crianças brasileiras de 4 a 8 anos de idade. As crianças foram avaliadas individualmente em ambiente de consultório, durante a execução de tarefas pré-determinadas, com moldes de atividades específicas, que compõem a School-AMPS. Sendo elas: recortar e colar casa e colar flor e colorir vaso de flor para as crianças de quatro e cinco anos de idade; recortar e colar dinossauro e colar barco e colorir fundo do mar para as crianças de sete e oito anos de idades; apenas as crianças de seis anos de idade puderam, inicialmente, 
escolher tarefas tanto para quatro quanto para oito anos. Cada criança foi avaliada em duas destas atividades, as quais foram propostas de acordo com a faixa etária de cada uma delas. O desempenho da criança em cada uma das atividades foi pontuado nas escalas de habilidades motoras e de processo.

Os educadores responderam um questionário composto por três questões, sendo uma fechada e duas abertas. A questão de número um buscou identificar, na percepção dos professores, em que extensão os dados do relatório correspondiam ao desempenho motor e de processo da criança observado em sala de aula. As alternativas de resposta eram: bom, regular ou ruim. $\mathrm{O}$ professor tinha como tarefa classificá-lo optando por uma dessas alternativas. As questões dois e três correspondiam às questões abertas. A questão dois tinha a finalidade de investigar possíveis incongruências entre os dados de avaliação das crianças obtidos em contexto de clínica e o desempenho apresentado em contexto de sala de aula. A questão três objetivou identificar a percepção dos educadores com relação às sugestões dadas pela Terapia Ocupacional quanto à viabilidade das estratégias pedagógicas, bem como mobiliário e recursos pedagógicos adaptados indicados para os alunos avaliados.

Os dados foram analisados de forma quantitativa $\mathrm{e}$ qualitativa.

A análise de dados da School-AMPS, foi feita com base na pontuação obtida pela criança em cada um dos itens das duas escalas, que pode variar de 1 a 4 , sendo: 1deficiente, 2-ineficiente, 3- questionável e 4-competente. Foi realizado a contagem de todos os itens pontuados como 1 ou 2, e em seguida a contagem de todos os itens pontuados como 3 ou 4. Tal contagem foi feita, separadamente, nas duas escalas e atividades realizadas pela criança. A partir da contagem desses itens, obteve-se uma pontuação final para cada escala e em cada atividade realizada. $\mathrm{O}$ desempenho da criança na realização da atividade foi considerado como deficitário, quando a criança recebeu pontuação 1 ou $2 \mathrm{em}$ mais de $50 \%$ dos itens avaliados na escalas de habilidades motoras ou de processo. Considerou-se desempenho satisfatório, quando a criança recebeu pontuação 3 ou 4 em mais de $50 \%$ dos itens avaliados nas escalas de habilidades motoras ou de processo. Caso a pontuação do desempenho fosse igual a $50 \%$, ou seja, nem deficitário e nem satisfatório, o desempenho da criança foi considerado como intermediário.

Finalizados os procedimentos supracitados, iniciouse a análise qualitativa com base na qualificação do desempenho apresentado pela criança, a qual foi estabelecida a partir do cálculo da porcentagem de pontos obtidos nas escalas de habilidades motoras e de processo da SchoolAMPS, conforme porcentagem descrita no parágrafo anterior. Esta análise permitiu visualizar se o desempenho da criança foi na sua maioria considerado satisfatório, deficitário ou intermediário, em cada atividade avaliada tanto na escala de habilidades motoras quanto na escala de habilidades de processo.

Foi feita também uma leitura sistemática dos dados da avaliação, visando analisar qualitativamente o desempenho da criança com o objetivo de elaborar um Relatório de Avaliação. Tal relatório continha exemplos da habilidade e/ou dificuldade apresentadas pelas crianças durante a avaliação, seguido de sugestões para os educadores de algumas estratégias viáveis para superar, em sala de aula, as dificuldades observadas a fim de viabilizar o desempenho do aluno e o acesso ao currículo. Este relatório foi apresentado aos professores de cada criança antes da aplicação do questionário.

Os dados do questionário de professores foram analisados quantitativamente e qualitativamente. A análise da questão de número um foi feita por meio da contagem da freqüência dada a cada alternativa de resposta. Os dados das questões de número dois e três foram categorizados de forma a atender os objetivos do estudo, ou seja, a unidade de análise foi composta por trechos de respostas agrupados por critério de semelhança.

\section{RESULTADOS E DISCUSSÃO}

Na Tabela 1 estão apresentados os dados referentes à caracterização das crianças participantes deste estudo, atividades realizadas e a pontuação final obtida nas Escalas de Habilidades Motoras (HM) e Escala de Habilidades de Processo (HP). As atividades estão identificadas pela letra $\mathrm{A}$, sendo que $\mathrm{A} 1$ refere-se à primeira atividade realizada, $\mathrm{e}$ A2 à segunda atividade realizada pela criança. Ressalta-se que a pontuação final é apresentada por meio do valor da porcentagem obtido em cada escala. A porcentagem que inclui os itens pontuados como 1 ou 2, refere que o desempenho da criança foi deficitário (def.). A porcentagem que inclui os itens 3 ou 4, determina desempenho satisfatório (satisf.). Cabe lembrar, que o desempenho foi considerado satisfatório quando a criança recebeu pontuação 3 ou 4 em mais de 50\% dos itens, e deficitário nos casos em que a criança obteve mais de $50 \%$ dos itens pontuados como 1 ou 2 . A classificação de desempenho intermediário (interm.) refere-se àquelas crianças que tiveram $50 \%$ dos itens pontuados como 1 ou 2 e $50 \%$ dos itens pontuados como 3 ou 4 . 
Tabela 1 - Caracterização dos participantes, atividade realizada e pontuação final nas escalas

\begin{tabular}{|c|c|c|c|c|c|}
\hline Participantes & $\begin{array}{l}\text { Diagnóstico } \\
\text { Clínico }\end{array}$ & Idade & $\begin{array}{l}\text { Atividades reali- } \\
\text { zadas }\end{array}$ & $\begin{array}{l}\text { Pontuação final - } \\
\text { Escala Motora }\end{array}$ & $\begin{array}{c}\text { Pontuação final - Escala } \\
\text { de Processo }\end{array}$ \\
\hline P1 & $\begin{array}{l}\text { Síndrome de } \\
\text { Kinsburne }\end{array}$ & 4 anos & $\begin{array}{l}\text { A1- recortar e } \\
\text { colar casa } \\
\text { A2- colar flor e } \\
\text { colorir vaso }\end{array}$ & $\begin{array}{l}81,25 \% \text { - def. } \\
68,75 \% \text { - def. }\end{array}$ & $\begin{array}{l}60 \% \text { - satisf. } \\
55 \% \text { - def. }\end{array}$ \\
\hline $\mathbf{P 2}$ & Hidrocefalia & 4 anos & $\begin{array}{l}\text { A } 1 \text { - recortar e } \\
\text { colar casa } \\
\text { A2 - colar flor e } \\
\text { colorir vaso }\end{array}$ & $\begin{array}{l}62,5 \% \text { - satisf. } \\
62,5 \% \text { - satisf. }\end{array}$ & $\begin{array}{l}60 \% \text { - def. } \\
60 \% \text { - def. }\end{array}$ \\
\hline $\mathbf{P 3}$ & $\begin{array}{c}\text { Paralisia Cerebral } \\
\text { hemiplégico }\end{array}$ & 5 anos & $\begin{array}{l}\text { A1 - recortar e } \\
\text { colar casa } \\
\text { A2- colar flor e } \\
\text { colorir vaso }\end{array}$ & $\begin{array}{c}81,25 \% \text { - def. } \\
75 \% \text { - def. }\end{array}$ & $\begin{array}{l}90 \% \text { - def. } \\
85 \% \text { - def. }\end{array}$ \\
\hline P4 & $\begin{array}{c}\text { Mielomeningocele } \\
\text { Hidrocefalia }\end{array}$ & 5 anos & $\begin{array}{l}\text { A1- recortar e } \\
\text { colar e casa } \\
\text { A2- colar flor e } \\
\text { colorir vaso }\end{array}$ & $\begin{array}{l}56,25 \% \text { - def. } \\
56,25 \% \text { - def. }\end{array}$ & $\begin{array}{l}50 \% \text { - interm. } \\
65 \% \text { - def. }\end{array}$ \\
\hline P5 & $\begin{array}{c}\text { Paralisia Cerebral } \\
\text { atáxica }\end{array}$ & 6 anos & $\begin{array}{l}\text { A1- colar barco e } \\
\text { colorir mar } \\
\text { A2- recortar e } \\
\text { colar dinossauro }\end{array}$ & $\begin{array}{l}87,5 \% \text { - def. } \\
87,5 \% \text { - def. }\end{array}$ & $\begin{array}{l}55 \% \text { - def. } \\
55 \% \text { - satisf. }\end{array}$ \\
\hline P6 & $\begin{array}{l}\text { Paralsia Cerebral } \\
\text { diplégica }\end{array}$ & 6 anos & $\begin{array}{l}\text { A1- recortar e } \\
\text { colar casa } \\
\text { A2- colar flor e } \\
\text { colorir vaso }\end{array}$ & $\begin{array}{l}87,5 \% \text { - def. } \\
81,25 \% \text { def. }\end{array}$ & $\begin{array}{l}80 \% \text { - satisf. } \\
85 \% \text { - satisf. }\end{array}$ \\
\hline P7 & $\begin{array}{l}\text { Malformação } \\
\text { congênita }\end{array}$ & 7 anos & $\begin{array}{l}\text { A1- recortar e } \\
\text { colar dinossauro } \\
\text { A2- colar barco e } \\
\text { colorir mar }\end{array}$ & $\begin{array}{l}68,75 \% \text { - satisf. } \\
68,75 \% \text { - satisf. }\end{array}$ & $\begin{array}{l}100 \% \text { - satisf. } \\
95 \% \text { - satisf. }\end{array}$ \\
\hline P8 & $\begin{array}{c}\text { Paralisia Cerebral } \\
\text { atáxica }\end{array}$ & 7 anos & $\begin{array}{l}\text { A1- colar barco e } \\
\text { colorir mar } \\
\text { A2- recortar e } \\
\text { colar dinossauro }\end{array}$ & $\begin{array}{l}68,75 \% \text { - satisf. } \\
62,5 \% \text { - satisf. }\end{array}$ & $\begin{array}{l}\text { 95\%- satisf. } \\
\text { 100\%- satisf. }\end{array}$ \\
\hline P9 & $\begin{array}{c}\text { Paralisia Cerebral } \\
\text { hemiplégica }\end{array}$ & 8 anos & $\begin{array}{l}\text { A1- colar barco e } \\
\text { colorir mar } \\
\text { A2- recortar e } \\
\text { colar dinossauro }\end{array}$ & $\begin{array}{l}75 \% \text { - def. } \\
75 \% \text { - def. }\end{array}$ & $\begin{array}{l}75 \% \text { - satisf. } \\
65 \% \text { - satisf. }\end{array}$ \\
\hline P10 & $\begin{array}{l}\text { Paralisia Cerebral } \\
\text { quadriplégica }\end{array}$ & 8 anos & $\begin{array}{l}\text { A1- colar barco e } \\
\text { colorir mar } \\
\text { A2- recortar e } \\
\text { colar dinossauro }\end{array}$ & $\begin{array}{l}93,75 \% \text { - def. } \\
93,75 \% \text { - def. }\end{array}$ & $\begin{array}{l}55 \% \text { - def. } \\
60 \% \text { - satisf. }\end{array}$ \\
\hline
\end{tabular}


De modo geral, os dados constantes da Tabela 1, evidenciam que as crianças apresentaram melhor desempenho na escala de habilidades de processo do que na escala de habilidades motoras, o que já era esperado, uma vez que os participantes do estudo apresentavam comprometimentos motores que repercutiram de formas variadas na pontuação obtida na escala motora.

Somente P2, P7 e P8 obtiveram desempenho satisfatório na escala de habilidades motoras nas duas atividades realizadas. Talvez, este desempenho tenha relação com as características motoras da criança e a demanda da tarefa realizada. Apesar de todas as crianças apresentarem déficits motores, que de fato influenciaram o desempenho das mesmas, o grau de dificuldade motora entre elas foi variável, tendo isto forte ligação com o diagnóstico clínico de cada uma delas. Crianças com déficits motores mais sutis como P2, P7 e P8 apresentaram desempenho mais satisfatório na atividade do que as crianças com déficits motores mais severos, pois as demandas das tarefas realizadas eram as mesmas para todas as crianças de acordo com a faixa etária.

P2 tem diagnóstico de hidrocefalia, de acordo com dados obtidos no prontuário a criança apresenta atraso no desenvolvimento motor, hipertonia de panturrilha bilateral e déficits de equilíbrio na postura ortostática. Tais características influenciaram a qualidade do desempenho, principalmente nas áreas da postura e mobilidade, no entanto, não interferiram na habilidade de desempenhar as atividades que exigiam as ações de membros superiores. Apenas P7 e P8, obtiveram desempenho satisfatório tanto na escala de habilidades motoras quanto de processo. Esse dado pode ser explicado pela característica do comprometimento motor. No caso de P7, este apresenta malformação nos quirodáctilos e alterações posturais (cifose torácica, ombros protrusos, escoliose à esquerda). Os déficits motores apresentados durante a avaliação possuem relação com as características motoras apresentadas por P7 que refletiram no seu desempenho no alinhamento postural, pois sua postura sentada e em pé era curvada e assimétrica. Apresentou dificuldade sutil para realizar movimentos finos com a mão direita relacionada com a amputação e polegarização do indicador da mão direita.

Com relação a P8, embora se saiba que o quadro de ataxia afeta a coordenação motora de membros superiores, sabe-se também que esta pode não ser tão deficitária quando comparada com quadros de hemiplegia ou quadriplegia. Nestes, o desempenho motor durante a realização de atividades que exijam destreza manual e coordenação motora fina pode ser mais deficitário.

Nota-se que a maioria das crianças que obteve desempenho satisfatório na escala de processo compreende a faixa etária entre 6 e 8 anos de idade. Crianças dessa faixa etária têm um período maior de atenção do que crianças entre 4 e 5 anos de idade. Possivelmente, as atividades propostas pela School-AMPS para as crianças de 4 e 5 anos de idade sejam de grande demanda cognitiva para essa faixa etária, talvez o ideal seria que as informações relevantes para a execução das atividades fossem minimizadas e mais direcionadas, com atividades de menor duração e com menos passos a cumprir.

Apresentam-se na seqüência os resultados advindos da análise do questionário. Os educadores serão identificados pela letra $E$. Com relação à percepção dos educadores quanto a qualidade do relatório de avaliação, ou seja, em que extensão os dados do relatório correspondem ao desempenho motor e de processo da criança observado em sala de aula, constatou-se que os dez educadores consideraram que o relatório de avaliação foi capaz de predizer de forma compatível o desempenho motor e de processo da criança observado em sala de aula. Tendo em vista que o relatório de avaliação apresentou estreita relação com o desempenho observado pelo educador em sala de aula, pode-se dizer que a School-AMPS permite a análise qualitativa baseada nos itens das escalas motoras e de processo e tem utilidade escolar, mesmo quando aplicada em ambiente de consultório.

Com relação à percepção dos educadores acerca de dados da avaliação incompatíveis com o desempenho da criança, dos dez educadores, três relataram divergências no desempenho de processo descrito no relatório de avaliação quando comparado ao desempenho observado em sala de aula. A divergência referiu-se aos itens: pergunta, atende e organiza da School-AMPS, conforme indicam as falas abaixo:

O que considero que não condiz com o desempenho da P1 é a questão de não fazer perguntas na sala de aula, P1 sempre tira suas dúvidas, faz perguntas. Acredito que talvez por não conhecer você (examinadora) não tenha feito perguntas. (E1).

Acho estranho o fato de que durante a avaliação P4 não se distraiu com facilidade, porque na sala de aula ela não mantém a atenção, faz um pouco da atividade e pára se distraindo com outras coisas, como conversas, com a atividade dos colegas. (E4).

Considero que P7 não mantém a atenção na sala de aula se distrai com muita facilidade. Também acho que na sala de aula ela não é muito organizada e cuidadosa com os materiais, pois derruba os 
materiais no chão, quebra sempre as pontas dos lápis e deixa na mesa os materiais de forma desorganizada. (E7).

Talvez a divergência relatada em relação ao item pergunta se deva ao fato de as crianças não terem proximidade com a examinadora, como apontou E1. É possível, pelo fato de as crianças não conhecerem a examinadora, não possuírem vínculo, elas tenham se sentido intimidadas para sanar suas dúvidas, apesar da disponibilidade da examinadora para tanto. Estas observações se fazem importantes, pois apontam para o possível diferencial da avaliação quando aplicada em ambiente controlado e quando aplicada em sala de aula. Na aplicação da avaliação em sala de aula, a qual representa o ambiente natural da criança, é possível que o item pergunta que faz parte da escala de processo receba melhor pontuação. Na rotina normal de sala de aula os questionamentos proferidos pelas crianças provavelmente são mais freqüentes, em virtude da familiarização com o educador.

Com relação à divergência relativa à atenção (atende), podemos atribuir à hipótese de a sala de aula ser composta por mais crianças, ter diferentes ruídos internos e externos, o que acaba por influenciar a atenção da criança, fazendo com que se distraia com mais facilidade. Reali (1984) apontou que algumas variáveis podem influenciar o ambiente físico, como: ruído, temperatura, iluminação e mobiliário. No ambiente escolar essas variáveis se fazem presentes e repercutem no desempenho do aluno, como observado no presente estudo. Segundo Vono-Coube, Bevilacqua e Fernandes (1999) apud Munhoz (2004), os ruídos da sala de aula podem ser gerados tanto fora da sala de aula, como brincadeiras e tráfego de veículos, quanto dentro da sala de aula, gerados por atividades humanas, como conversar, andar e recortar papel.

O contexto da avaliação foi totalmente diferente do contexto de uma sala de aula. A avaliação foi realizada em ambiente de clínica, individualmente, sem maiores ruídos internos ou externos e com a atenção da examinadora exclusivamente voltada para a criança. Essa discrepância entre os dois contextos provavelmente influenciou as respostas das crianças, que se mostraram mais atentas no ambiente clínico.

Outro aspecto que pode ter influenciado a atenção é a idade cronológica das crianças avaliadas. P4 tinha 5 anos de idade, sendo que Gesell (1993) enfatiza que crianças desta faixa etária mudam facilmente de atividade, permanecem atentas nas atividade cerca de vinte minutos, em geral completam sua tarefa, embora possam desviar a atenção para observar o trabalho de outra criança ou procurar o educador para lhe contar uma experiência pessoal, ou ainda para mostrar-lhe aquilo que está fazendo.

A atividade dirigida, proposta na School-AMPS, tem duração de no máximo 20 minutos cada uma, sendo que destes, 15 minutos são para realizar a tarefa e o restante do tempo, 5 minutos, para guardar o material. As crianças recebem estas instruções antes de iniciar a tarefa. Este fato somado as condições ambientais apropriadas, provavelmente, favoreceram a manutenção da atenção da criança durante a realização da atividade.

Com relação à divergência relativa à organização dos materiais (organiza), podemos atribuir tal desempenho ao fato das instruções da avaliação enfatizar muito a organização dos materiais, a necessidade de escolher e pegar somente os materiais que irá precisar para realização da tarefa, este enfoque possivelmente tenha beneficiado o desempenho de $\mathrm{P} 7$.

No que se refere à percepção dos educadores com relação às sugestões dadas pela Terapia Ocupacional quanto à viabilidade das estratégias pedagógicas, bem como mobiliário e recursos pedagógicos adaptados indicados para os alunos avaliados, os resultados revelam que todos os educadores consideraram viáveis as sugestões e estratégias oferecidas no Relatório de Avaliação, conforme indicam as falas abaixo:

Gostei bastante. Acho que sempre deveria haver esse contato entre o terapeuta ocupacional e a escola, porque contribuiu bastante as informações que você trouxe para a gente trabalhar com P3, mas infelizmente isso pouco acontece. Temos poucas informações sobre P3. (E3).

Acredito que as idéias quanto a organização do material podem ajudar P7 na sala de aula, farei da forma sugerida na avaliação, talvez dê certo na sala de aula também. (E7).

Achei que o relatório vai ajudar bastante P8. Não conhecia a pulseira de chumbo, acho que pode ajudá-la. (E8).

De acordo com os professores, participantes deste estudo, a aplicação da School-AMPS em ambiente controlado não apresentou discrepância significativa em relação ao comportamento motor e de processo observado em sala de aula. Este dado mostra que a School-AMPS parece ser um instrumento extremamente útil para que terapeutas ocupacionais, em parceria com os professores, avaliem o desempenho funcional do aluno e elaborem estratégias que possam contribuir para que o processo de ensino e 
aprendizagem seja eficaz, considerando as especificidades de cada aluno, principalmente as do aluno com deficiência.

\section{CONCLUSÕES}

A School-AMPS possibilitou identificar em quais itens da escala de habilidades motoras e de processo as crianças apresentaram desempenho considerado deficitário ou satisfatório, ou seja, apontou as habilidades como também as dificuldades que são inerentes ao aluno e as que são inerentes às atividades.

Em relação aos dados obtidos através do questionário aplicado aos educadores, há evidências de que todos consideraram que o relatório de avaliação prediz de forma compatível o desempenho motor e de processo da criança observado em sala de aula. Também consideraram viáveis os possíveis recursos pedagógicos adaptados e estratégias para superar as dificuldades observadas na avaliação ou potencializar o desempenho do aluno em sala de aula.

$\mathrm{O}$ relatório de avaliação possibilitou ao professor uma reflexão sobre a qualidade e o modo como a tarefa era desempenhada na escola, evidenciando as habilidades e potencialidades do aluno durante sua realização, como também os aspectos funcionais que devem ser estimulados no contexto educacional. A utilização da School-AMPS no contexto natural de sala de aula poderá permitir melhor detecção de aspectos que interferem no desempenho do aluno com deficiência física frente às atividades escolares, considerando os componentes de desempenho do aluno, bem como as demandas da tarefa e do ambiente.

BALEOTTI, L. R.; ZAFANI, M. D.; FARIA, M. G. A.; MAGALHÃES, L. C. Teachers’ perception about the school-version of the assessment of motor and process skills applied to disabled students. Rev. Ter. Ocup. Univ. São Paulo, v. 22, n. 1, p.1-9, jan./abr. 2011.

\begin{abstract}
This study aims to verify under the teacher's point of view if the School Version of the Assessment of Motor and Process Skills (School - AMPS) applied to disabled students predicts the student's performance observed in the classroom. Ten disabled children, between four and eight years old, and their respective teachers participated on this research. The data was obtained through observation of children in clinical environment during the accomplishment of predetermined tasks, concerning the School-AMPS Brazilian version. The teachers were given a child's assessment report and applied a questionnaire composed of three questions. The data was analyzed quantitative and qualitatively. The results show that the School - AMPS made possible to identify if the child's performance was mostly considered deficient, satisfactory or intermediate and, moreover, it made possible to analyze the performance based on the perception of the existing relation among the person's demands, the task and the environment. The teachers have considered that the assessment report presented predicts compatibly the student's performance observed in the classroom. They have considered feasible the adapted pedagogical resources and the suggestions of strategies to minimize and/or overcome the difficulties observed in the student's performance. It has been concluded that the School - AMPS Brazilian version has potential as a functional performance measure on disabled children, between four and eight years old, and it may contribute to the occupational therapist's performance in the school context.
\end{abstract}

DESCRITORES: Education, special; Disabled person; Occupational therapy.

\section{REFERÊNCIAS}

ATCHISON, B. T.; FISHER, A. G.; BRYZE, K. Rater reliability and internal scale and person response validity of the school assessment of motor and process skills. American Journal of Occupational Therapy, v. 52, n. 10, p. 843-850, 1998.

BALEOTTI, L. R. Um estudo do ambiente educacional inclusivo: descrição das atitudes sociais e das relações interpessoais de deficiente. 2006. 184 f. Tese (Doutorado em Educação) - Faculdade de Filosofia e Ciências, Universidade Estadual Paulista, Marílía.
BRASIL. Ministério da Educação.Conselho Nacional de Educação. Resolução CNE/CEB no 2, de 11 de setembro de 2001. Institui Diretrizes Nacionais para a Educação Especial na Educação Básica. Diário Oficial da República Federativa do Brasil. Brasília, DF, 14 set. 2001.

FARIA, M. G. A. Adaptação da avaliação de habilidades motoras e de processo - versão escolar - para crianças brasileiras de 4 a 8 anos de idade. 2004. Dissertação (Mestrado) - Universidade Estadual de Minas Gerais, Belo Horizonte. 
BALEOTTI, L. R. et al. Percepção de professores. Rev. Ter. Ocup. Univ. São Paulo, v. 22, n. 1, p. 1-9, jan./abr. 2011.

FARIA, M. G. A.; MAGALHÃES, L. C. Adaptação da AMPSescolar para crianças brasileiras de 4 a 8 anos. Psicologia em Estudo, Maringá, v. 11, n. 3, p. 493-502, 2006.

FINGERHUT, P., et al. Classroom-based assessment: validation for the school AMPS. American Journal of Occupational Therapy, v. 56, n. 2, p. 210-213, 2002.

GESELL, A. A criança dos 5 aos 10 anos. 2a ed. São Paulo: Martins Fontes, 1993. (Psicologia e pedagogia).

MUNGUBA, M. C. Inclusão escolar. In: CAVALCANTI, A.;
GALVÃO, C. Terapia ocupacional: fundamentação \& prática. Rio de Janeiro: Guanabara Koogan, 2007. p. 519-525.

MUNHOZ, L. G. Intensidade vocal do professor e ruido de fundo da sala de aula. 2004. 122f. Dissertação (Mestrado em Educação) - Faculdade de Filosofia e Ciências, Universidade Estadual Paulista, Marília.

REALI, A. M. M. R. Proposta de uma metodologia de avaliação ambiental para sala de aulas. 1984. 112 f. Dissertação (Mestrado em Educação Especial) - Universidade Federal de São Carlos, São Carlos.

Recebido para publicação: 11/02/11

Aceito para publicação:30/04/11 